\title{
Im Überwachungsstaat
}

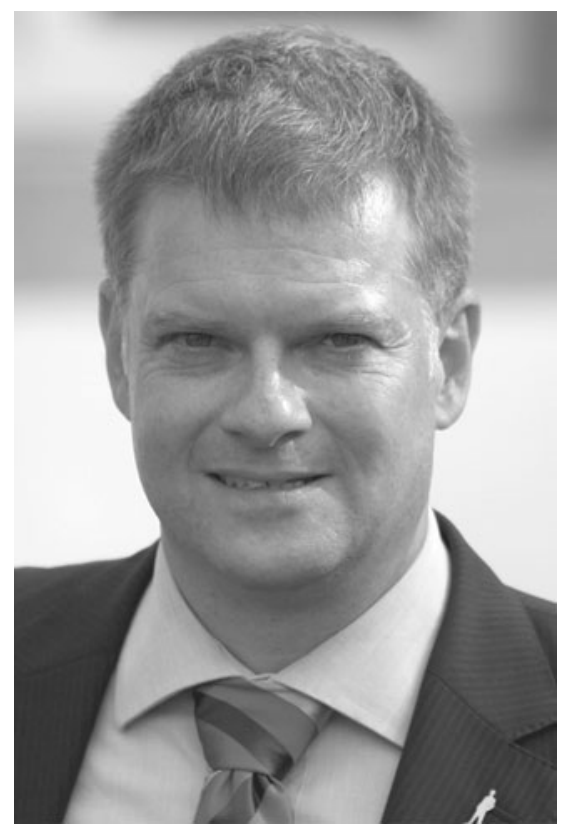

Es war ein Jubiläum, das niemand beging. 30 Jahre Macintosh wurde 2014 gefeiert nicht aber das 30. Jahr nach „1984“, dem Jahr, für das George Orwell 1948 einen allumfassenden Überwachungsstaat erwartete. Hatten wir vielleicht gar keinen Grund mehr, etwas zu feiern? Oder wirkte der Schock der Veröffentlichungen Edward Snowdens noch nach, so dass wir das Feiern vergaßen? Oder ging es uns eher so, dass wir das alles ohnehin schon ahnten (oder zu wissen glaubten) - schließlich ist es doch naheliegend, dass ein Geheimdienst sich schnappt, was er kriegen kann?

Vielleicht ist die Ursache aber viel beunruhigender: Stecken wir möglicherweise in der Haut des Froschs im Kochtopf, dessen Wasser nicht kocht, sondern langsam und schleichend erwärmt wird? Fragen wir uns vielleicht: Ist es schon zu spät oder noch nicht? Können wir überhaupt (noch) etwas tun? Oder blenden wir die allgegenwärtige Überwachung bereits aus und reden uns (schon wieder oder immer noch) ein, dass wir ja nichts zu verbergen haben? Es ist ja auch noch nichts passiert (zumindest haben wir nichts davon gemerkt), und böse Tyrannen gibt es nur in Schulbüchern oder Nachrichtensendungen über entlegene Teile der Welt. Warum sollten wir uns also beunruhigen?

Wenn wir die Realität nicht zumindest abschnittweise ausblenden oder verleugnen, wird es jedenfalls unbequem. Wer mag noch Whatsapp, GMail oder Facebook nutzen, wenn er sich vorstellt, dass jede ausgetauschte Nachricht und jeder "Like"-Mausklick, jeder Chat und jede Internet-Suche mitgeschnitten, beobachtet und zu einem Bild mit Bewegungsprofil verdichtet wird, das nie mehr jemand löscht und jederzeit ausgewertet werden kann?

Aber das Smartphone ausschalten? Dann ist man doch nicht erreichbar! E-Mails verschlüsseln? Dann kann man sie ja nicht mehr mit jedem Client abrufen! Auf das Navi verzichten? Wer hat denn heute noch einen Autoatlas dabei? („Papi, was ist ein Autoatlas?")

Derweil nehmen Datendienste und Erfassungen zu, schrumpft der Bereich, in dem unser Verhalten höchstens im Gedächtnis unserer Mitmenschen vergängliche Spuren hinterlässt: "Car-IT" sorgt für eine sorgsame Begleitung unseres Fahrverhaltens (Wie sparsam ist der Fahrstil? Welche Strecken werden gewählt? Wo wird ein Stoppschild überfahren, eine Geschwindigkeitsbeschränkung überschritten oder ein Parkverbot missachtet? Wie heftig sind die Bremsungen?). Zugleich steuert unser "SmartHome" unseren Energieverbrauch, analysiert unsere Gewohnheiten und speichert unsere Präferenzen - jede Minute, die wir in unserem Zuhause verbringen. Und wenn wir schließlich in den Fernsehsessel sinken, erfreut uns "SmartTV" mit einem an die von uns erlernten Interessen und Wünsche angepassten Programm- und Nachrichtenangebot.

Vielleicht war es ja ganz richtig, im Jahr 2014 nicht an „1984“ zu denken. Denn Orwell hatte wahrscheinlich die falsche Vision. Was uns wirklich bevorsteht hat Ray Bradbury in seinem (1966 von François Truffaut genial verfilmten) Roman „Fahrenheit 541" vorausgesehen: Wir leben in einem technologischen Wunderland, rundumversorgt und perfekt unterhalten, bei umfassender Kontrolle (zu unserer eigenen Sicherheit) - und haben vor lauter Unterhaltungsglück vergessen, wie Freiheit und Erkenntnis schmecken.

Im Jahr 2013 hätten wir den 60. Geburtstag des Büchleins feiern können. Dem Jahr, in dem Snowden uns die Augen geöffnet hat. Aber so richtig hingucken wollen wir dann doch lieber nicht.

\section{Dirk Fox}

